\title{
Retinoblastoma: A Retrospective Study of 27 Cases in University Hospital of Lubumbashi-RDC
}

\author{
Ilunga $\mathrm{JN}^{*}$, Lukamba $\mathrm{RM}^{2}$, Chenge $\mathrm{G}^{3}$, Numbi $\mathrm{MN}^{3}$, Kanteng $\mathrm{G}^{2}$, Mutoke $\mathrm{G}^{2}$, Kyabu $\mathrm{VK}^{1}$ and Mwenze $\mathrm{DM}^{1}$ \\ ${ }^{1}$ Pathology Department, University Hospital of Lubumbashi (DRC), Lubumbashi, Congo \\ ${ }^{2}$ Paediatric Oncology Department, University Hospital of Lubumbashi (DRC), Lubumbashi, Congo \\ ${ }^{3}$ Ophtalmology Department, University Hospital of Lubumbashi (DRC), Lubumbashi, Congo
}

*Corresponding author: Ilunga JN, Pathology Department, University Hospital of Lubumbashi (DRC), Lubumbashi, Congo, E-mail: nijulien2011@yahoo.com

Citation: Ilunga JN, Lukamba RM, Chenge G, Numbi MN, Kanteng G, et al. (2016) Retinoblastoma: A Retrospective Study of 27 Cases in University Hospital of Lubumbashi-RDC. J Cancer Sci Clin Oncol 3(2): 206. doi: 10.15744/2394-6520.3.206

Received Date: June 03, 2016 Accepted Date: September 07, 2016 Published Date: September 09, 2016
Abstract
We conducted a retrospective study on 27children with retinoblastoma in the Lubumbashi University Hospital between January 2008 and October 2012. Al cases were diagnosis clinically and 11 cases were confirmed by histology.
Sixteen children (59.3\%) were male and 11 female (40.7\%). Unilateral involvement of the eye was noticed in 24 patients (88.9\%) and bilateral in 3 cases $(11.1 \%)$.
The average age was $3 \pm 1.4$ years in girls and $3.3 \pm 1.9$ years in boys. Eight patients $(29.6 \%)$ were treated by surgery only, 3 went thought surgery plus chemotherapy (11.1\%), and 7 patients (25.9\%) were treated by chemotherapy only. Nine patients (33.3\%) did not receive any specific treatment.
The follow-up of patients made in 2013 reported complete remission in 2 patients (7.4\%), partial remission in 3 patients (11.1\%), recurrence in 2 patients $(7.4 \%), 10$ patients (37\%) were dead and $10(37 \%)$ were lost from view.
Our study indicates needs for early diagnosis and special care to improve the prognosis of retinoblastoma in DRC.
Keywords: Retinoblastoma; Follow-up

\section{Introduction}

Retinoblastoma is a one of the most malignant tumors in infants. The frequency and the prognosis make it an important tumor [1]. Retinoblastoma can be diagnosed clinically through direct signs such as exophthalmos, strabismus, nystagmus or leukokoria. Most cases of retinoblastoma in Africa are diagnosed at a late stage, high rate of death is the final end. In cases of early diagnosis, surgery treatment is hardly accepted in Sub Saharan Africa.

There is not a cancer registry in the Democratic Republic of Congo. Cancers related publications are also very rare. Thus, there is no reliable statistics on cancer in general and on ocular cancers of the child. Kayembe, et al., Kaimbo, et al., Poso, et al. and Kazadi, et al. reported some cases of retinoblastoma in Kinshasa in northern part of the Democratic Republic of Congo. In all these studies, the diagnosis was made clinically [2-5].

The main of this study is to complete knowledge of cancers, particularly retinoblastoma data. We conducted this retrospective study specifically to determine epidemiological, clinical and pathological data in retinoblastoma patients in the university hospital clinics (CHU) of Lubumbashi (DRC) in (DRC).

\section{Patients and Methods}

Twenty seven cases were diagnosed clinically as retinoblastoma from January 2008 to October 2012.

Pathological studies were conducted on all surgical cases (11 vs 27). Data were collected from hospital and pathology registries.

\section{Parameters}

Many desired parameters were taken in consideration: age, gender, anatomical site (right eye, left or bilateral disease), treatment (surgery only, surgery plus chemotherapy, chemotherapy alone or no treatment) and the evolution of patients Partial Remission(PR), Complete Remission(CR), Death(D), Recurrence(REC) or lost from view. 


\section{Legends and explanations}

$\mathrm{PR}=$ Patients still have retinoblastoma in regression and are under treatment (Surgery not yet completed). REC : Disease appear again after surgery. CR : Disease completely removed.

\section{Chemotherapy}

Conventional chemotherapy was alternative cycles of cyclophosphamide+vincristine and carboplatine+etoposide. Metronmic chemotherapy was cycles of 6 weeks: 3 weeks of cyclophosphamide per os $25 \mathrm{mg} / \mathrm{m} 2 /$ day and 4 vincristine iv 1,5mg/m2/week; followed by 3 weeks Methotrexate per os $15 \mathrm{mg} / \mathrm{m} 2 /$ day.

Data were collected and entered on a computer in the program Excel 2012. Statistical analysis was based on the calculation of the frequency, mean and standard deviation.

\section{Results}

The 27 patients with retinoblastoma this study was aged 1 to 8 years. The mean age was $3.2 \pm 1.7$ years. There were 11 girls and 16 boys $(40.7 \%$ and $59.3 \%)$. The average age of girls was $3 \pm 1.4$ years and $3.3 \pm 1.9$ years for boys (Table1). Patient with unilateral retinoblastoma was aged 1 to 8 years. Those with bilateral involvement were aged 1 to 3 years. There were 6 patients (22.2\%) with involvement of the right eye , 11 for left eye (40.7\%), and 7 other unilateral not determined, meaning $88,9 \%$ cases of unilateral involvement. Bilateral involvement was observed in 3 cases or in $11.1 \%$ of cases (Table 2).

\begin{tabular}{|c|c|c|c|c|}
\hline & Nb & \% & Minimal Age & Maximal Age \\
\hline All 3.2 years & 27 & 100 & 1 year & 8 years \\
\hline Girls 3 years & 11 & 40.7 & 1 year & 5 years \\
\hline Boys 3.3 years & 16 & 59.3 & 1 year & 8 years \\
\hline Unilateral & 24 & 89 & 1 year & 8 years \\
\hline Bilateral & 3 & 11 & 1 year & 3 years \\
\hline
\end{tabular}

Table 1: Age of patients

\begin{tabular}{|c|c|c|}
\hline & Nb & \% \\
\hline Right eye & 6 & 22.2 \\
\hline Left eye & 11 & 40.7 \\
\hline Both eyes & 3 & 11,1 \\
\hline Site not determined & 7 & 25.9 \\
\hline
\end{tabular}

Table 2: Laterality

Eight patients (29.6\%) were treated by surgery only, 3 went thought surgery plus chemotherapy (11.1\%). Seven patients (25.9\%) were treated only with chemotherapy and 9 or $33.3 \%$ did not receive any treatment. The follow-up of patients made in 2013 reported 3 patients (11.1\%) with partial remission, 2 with recurrences (7.4\%), 10 cases of dead patients (37\%), 2 patients with complete remission and 10 patients (37\%) were lost for view (Tables 3 and 4 ).

\begin{tabular}{|c|c|c|}
\hline & Nb & \% \\
\hline Partial Remission & 3 & 11.1 \\
\hline Recurrence & 2 & 7.4 \\
\hline Dead & 10 & 37 \\
\hline Lost from view & 10 & 37 \\
\hline Complete Remission & 2 & 7,4 \\
\hline
\end{tabular}

Table 3: Status at the time of follow-up

\begin{tabular}{|c|c|c|c|c|c|c|}
\hline \multicolumn{7}{|c|}{ Treatment Status } \\
\hline TOTAL & CR & PR & REC & D & LV & \\
\hline Surgery only & 0 & 0 & 0 & 2 & 6 & 8 \\
\hline $\begin{array}{c}\text { Surgery + } \\
\text { Chemotherapy }\end{array}$ & 0 & 1 & 0 & 1 & 1 & 3 \\
\hline Chemotherapy only & 2 & 2 & 2 & 1 & 0 & 7 \\
\hline No treatment & 0 & 0 & 0 & 6 & 3 & 9 \\
\hline
\end{tabular}

$\mathrm{CR}=$ complete remission; $\mathrm{PR}=$ partial remission; $\mathrm{REC}=$ Recurrence; $\mathrm{D}=\mathrm{Dead} ; \mathrm{LV}=$ lost from view Table 4: Correlation Status/Treatment 


\section{Discussion}

Retinoblastoma is mainly a cancer of children. Although it has been reported in the first year of life and extreme age as 8 years, the highest incidence is generally reported around 3 years in most publications. In Kinshasa (another city of the Democratic Republic of Congo), Kazadi, et al. reported the average age of less than 1 year [5]. Kayembe, et al. observed the tumor at an average age of 2.4 years in 1986 [2]. Hassan, et al. in Egypt, Hamadi, et al. and Mali and Sethis, et al. reported an average age of 3 years as observed in this study [6-8]. But, Saiju, et al. and Zucker, et al. reported the average age of diagnosis around 2 years $[9,10]$. These differences may be related to the known evolution of retinoblastoma and to the concern of physicians to its clinical presentation. Retinoblastoma is indeed a tumor that may remain unnoticed during relative long time. Between simple signs such as nystagmus, leukokoria and exophthalmia or tumor syndrome, there may be a long way. The tumor development could also be influenced by factors poorly understood. In most publications, data are not well reported about the stage of tumor. Cohort studies taking into account the stage of the tumor could provide an explanation for these differences in age at diagnosis.

Retinoblastoma is a cancer that occurs in both genders. In several publications as in our study, boys are more affected than girls. These observations were reported by Hamadi, et al. Sethi, et al., and Kayembe, et al. [2,7,9]. For Ba-Saddik, et al. retinoblastoma is reported more in girls than compared to boys [11]. Retinoblastoma is mostly a unilateral tumor $[2,7,8,12,13]$.

But bilateral tumors have been observed by Saiju, et al. [9]. Bilateral retinoblastoma is usually genetic and hereditary diseases [1]. Death is rapidly the usual spontaneous issue of retinoblastoma. But the prognosis can be improved through specific treatments in case of early diagnosis. Treatment choice depends on the tumor stage [14]. Retinoblastoma is a disease that requires multidisciplinary and life management by ophthalmologist, pediatrician oncologist and in some cases radio therapist. In Kinshasa, all the patients were cure only by surgery [2]. In our study, 8 patients (29.6\%) were treated only by surgery, 7 patients (25.9\%) treated by chemotherapy only and 3 patients (11.1\%) by surgery plus chemotherapy. Nine patients (33.3\%) did not receive any treatment because they were lost just after diagnosis or have no money for treatment. Thirty seven percent of patients were dead at the time of follow- up and the number of loss of view patients is very higher (37\%). Kazadi, et al. reported $92.5 \%$ cases of mortality [5]. These data indicate needs for early diagnosis and special care to improve the prognosis of retinoblastoma in Congo Kinshasa.

\section{Conclusions}

This retrospectively study was conducted on 27 patients with retinoblastoma in Lubumbashi from 2008 to 2012 . The average age of patients is 3.2 years. The disease affects boys in 59\% and girls in $41 \%$. Bilateral involvement is found in $7 \%$ of cases at the maximal age of 3 years. Most of the patients are dead or lost from view at the follow-up time.

\section{Acknowledgments}

We give special thanks to Medical Students of the University of Lubumbashi for helping us to collect data. We also are thankful to Professor Jean Le Merle, the Founder of the Franco-African Pediatric Oncology Group (GFAOP) for supporting the medical treatment of childhood cancer in the Democratic Republic of Congo.

\section{References}

1. Iris Lucien (1972) Histopathologie oculaire. Edition Masson et Compagnie, Paris 112-9.

2. Kayembe L (1986) “Retinoblastoma: 21- year review," J Français d’Ophtalmologie 9: 561-5.

3. Kaimbo DK, Kilangalanga J, Missotten L (1995) Exophtalmia in Zaire. Bull Soc Belge Ophtalmol 259: 199-204.

4. Poso MY, Mwanza JC, Kayembe DL (2000) Malignat Tumors of the eye and adnexain Congo-Kinshasa. J Fr Ophtalmol 23: 327-32.

5. Lukusa AK, Aloni MN, Kadima-Tshimanga B, Mvitu-Muaka M, Ehungu JLG (2012) Retinoblastoma in the Democratic Republic of Congo: 20-Year Review from a Tertiary Hospital in Kinshasa. J Cancer Epidemiol doi.org/10.1155/2012/920468.

6. Hassana SA, Massoudg AA, Hussain GH (1992) Retinoblastoma in Upper Egypt (1981-1991). Saudi J Ophthalmol 6: $32-8$.

7. Sibedi H (2009) Études des aspects épidémio - cliniques du rétinoblastome dans le service de pédiatrie du Centre Hospitalier Universitaire GABRIEL TOURE au MALI.

8. Sethi S, Pushker N, Kashyap S, Sharma S, Mehta M, et al. (2013) Extraocular retinoblastoma in Indian children: clinical, imaging and histopathological features. Int J Ophthalmol 6: 481-6.

9. Saiju R, Moore G, Shrestha U, Shrestha MK, Ruit S (2013) Retinoblastoma: geographic distribution and presentation at a tertiary eye care centre in Kathmandu, Nepal. Nepal J Ophthalmol 5: 169-76.

10. Zucher Rétinoblastome: Revue pratique paris, 1993Kargougou. Les tumeurs orbito - oculaires au Burkina Faso: aspects anatomopathologiques, épidémio cliniques et thérapeutique à propos de 119 cas colligés de 1983 à 1997.

11. Ba-Saddik IA (2013) Childhood cancer in Aden, Yemen. Cancer Epidemiol 37: 803-6.

12. Doutetien C, Oussa g, Babagbeto M, Bassabi SK (1999) Le rétinoblastome au centre national hospitalier universitaire de COTONOU (à propos de 24 cas). Le Benin Médical.

13. Gündüz K, Köse K, Kurt RA, Süren E, Taçyildiz N, et al. (2013) Retinoblastoma in Turkey: results from a tertiary care center in Ankara. J Pediatr Ophthalmol Strabismus 50: 296-303.

14. McDCartney A.C.E (1995) Tumors of the eye and adnexae in Christopher D. M. Fletcher ( $4^{\text {th }}$ edn). Diagnostic Histopathology of Tumors. Edinburgh, Chuirchill livingstone 2: 1267-87. 


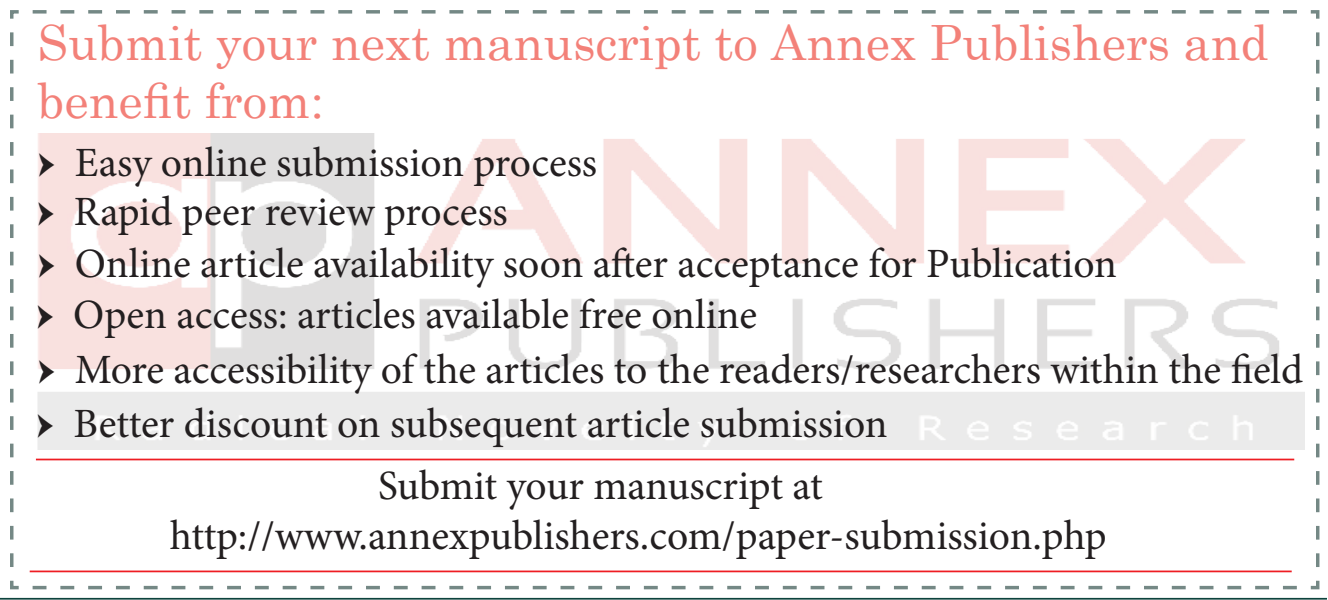

